\title{
Primary immunodeficiency diseases: when we should suspect
}

\begin{abstract}
Primary immunodeficiencies are a wide range of more than 180 diseases caused by genetic defects in one or more components of the immune system. These diseases present highly variable clinical aspects, including patients with severe genetic defects that are incompatible with normal life. Therefore, a timely diagnosis contributes to improve the quality of life of patients, as well as reduces the risk of complications and death. Thus, it is essential that the physician in primary approach is able to perform a suspicion consistently to allow the initiation of the investigation. This paper discusses the key features of primary immunodeficiencies as well as the determinants of clinical suspicion and early diagnosis. A review of the literature published over the last ten years was carried out in the last ten years in the databases of Scielo, LILACS, Google Scholar, PubMED in addition to book chapters and the Professional Society sites: SBP (Brazilian Society of Pediatrics) and support Organization: BRAGID (Brazilian Group for Immunodeficiencies).
\end{abstract}

Keywords: primary immunodeficiency, clinical signs, diagnosis, review
Volume 4 Issue 5 - 2019

\author{
Simara Zabulon de Albuquerque Bastos,' \\ Maria Valéria Leimig Telles,' Rodrigo \\ Emmanuel Leimig Telles Parente,' Lucas \\ Leimig Telles Parente,' Bruno da Rocha Alves \\ Lira,' Leonardo Nunes Ferreira,' Fernando \\ Gomes Figueredo,, ${ }^{1,2}$ Maria das Graças \\ Nascimento Silva' \\ 'Faculty of Medicine Estácio de Juazeiro do Norte- FMJ, Juazeiro \\ do Norte, Brazil \\ ${ }^{2}$ Department of Development and Technological Innovation in \\ Medicines, Federal University of Ceará-UFC Fortaleza, Brazil
} Correspondence: Fernando G Figueredo, Estadio de Juazeiro
do Norte Medical School Av, Tenente Raimundo Rocha,
515-University City-Juazeiro do Norte-Ceará-sPostal Code
63.048-080,Tel (088) 3572-78I3, Email fgfigueredo@gmail.com

Received: August 27, 2019 | Published: October 16, 2019

\section{Introduction}

A functional immune system is fundamental for homeostasis because it plays essential roles in defense against infectious agents, besides protecting the human body against tumor cells and autoimmune diseases. During childhood, the immune system is physiologically immature, but it develops progressively as the individual grows. Thus, in this period, recurrent infections can occur, mainly in the airways, even in completely healthy children. ${ }^{1,2}$ Children that born with a defective immune system develop conditions that belong to a group of diseases known as primary immunodeficiencies (PIDs). ${ }^{3-5}$ These congenital diseases (which develop mainly during childhood) manifest especially in the form of recurrent infections, which often coincide with the immunological maturity period of the patients. ${ }^{6-8}$ Therefore, recognizing the suggestive characteristics in the clinical history and during the physical examination is fundamental to raise the hypothesis of primary immunodeficiency. ${ }^{3}$ Given the many characteristics that serve as warning signs, the Jeffrey Modell Foundation in association with the American Red Cross has created a list of Ten Warning Signs to facilitate the medical reasoning during the care of patients who need initial laboratory investigation ${ }^{9}$ The investigation should be carried out through initial examinations of easy access, which may be requested by the professional in the primary approach. ${ }^{7}$ The diagnosis should be complemented with specialized examinations in reference centers, where the child should receive prompt treatment. ${ }^{10}$ An early diagnosis is fundamental for an adequate treatment and consequent improvement in the quality of life of the patient, as well in the long-term prognosis and prevention of sequelae. Therefore, the recognition of the need of a systematic investigation for primary immunodeficiency of the patient depends on a well-founded suspected diagnosis by the physician in the primary approach.

\section{The immune system}

The immune system is an organization of specialized cells and molecules whose main functions are: defense against infectious microorganisms, destruction of tumor cells and protection against autoimmune diseases ${ }^{11}$ The onset of the immune system development occurs during the embryonic and fetal phase, reaching maturity only in adolescence and therefore, the physiological immaturity of immunity is inherent in newborns and infants. ${ }^{1,2}$ Immunoglobulin $\mathrm{M}$ (IgM) begins to be produced at the 15 th week of gestation and reaches $60 \%$ of the values found in an adult at age of 1 year. Only at the 30th week of gestation, the production of IgG begins, and almost every IgG in the newborn is of maternal origin. This maternal antibody undergoes a catabolism process between the $4^{\text {th }}$ to $8^{\text {th }}$ month of life. This period is also characterized by a low production of immunoglobulin, corroborating to the so-called physiological hypogammaglobulinemia period, which may extend up to 4 or 5 years of age and therefore, children are more susceptible to recurring infections. Satisfactory levels of IgG (like those of an adult) are reached only at age of 8-12 years. ${ }^{1,12}$

Immunoglobulin A ( $\operatorname{IgA}$ ) plays a key role in the defense against pathogens and allergens that penetrate the mucous membranes of the respiratory and gastrointestinal tract. However, the levels of this antibody are very low at birth. In this context, the stimulation through breastfeeding is of immense importance, because the colostrum and milk of the mother contain high concentrations of IgA that is specific for several respiratory pathogens. Over the years there is a progressive 
increase in IgA production, which stabilizes at age $12 .{ }^{13}$ Finally, IgE antibodies are also produced at low levels by the fetus due to poor antigenic stimulation. ${ }^{10}$ Another characteristic of the immune response in childhood is that an efficient response to polysaccharide antigens (T-independent response) occurs only after 18 months of life. ${ }^{14}$

Although many infections may occur in this period of physiological immaturity, the susceptibility to recurrent infections in certain children should have as differential diagnosis the primary immunodeficiencies. ${ }^{15}$ In addition to recurrent infections, other conditions may also be associated, such as autoimmune diseases, inflammatory diseases, and cancer. The onset of symptoms usually occurs in the first months of life, but may also occur late in childhood, adolescence and even in adulthood. ${ }^{6}$ The PIDs are considered rare diseases with a prevalence of 1:2000. The incidence of PIDs is variable according to the type of immunodeficiency. Thus, humoral immunodeficiency is type responsible for most cases and complement deficiencies are the rarest. ${ }^{16}$ In most cases, the PIDs are determined by an autosomal X-linked inheritance and autosomal recessive inheritance, justifying the higher prevalence in male children $(5: 1)$ and populations with high consanguinity rates, respectively. ${ }^{17,18}$

According to the component of the immune system that is affected, the PIDs can be classified into 8 groups. ${ }^{19}$ a) Predominant antibody deficiencies; b) Combined deficiencies (T\&B cells); c) Other clearly defined immunodeficiencies; d) immunological dysregulation disorders; e) Congenital defects of phagocytes; f) Defects of innate immunity; g) Autoinflammatory syndromes; h) Complement system deficiencies. $^{20,21}$

\section{When we should suspect}

Recurrent infections are the most common clinical manifestations of the PIDs. ${ }^{15}$ However, healthy children without associated comorbidities may also have recurrent infections, especially in recurrent respiratory infections (RRI), which are among the most common complaints in the pediatric clinical practice..$^{22}$ The definition of RRI considers at least one of the following conditions: 1) six or more respiratory infections per year; 2) one or more monthly respiratory infections; 3 ) three or more annual infections of the lower respiratory tract..$^{20,21,23}$ Healthy children can present 6 to 10 episodes of airway infections per year (sometimes, up to 12 episodes per year), accounting for $50 \%$ of all infections of the respiratory tract (IRT), from which $30 \%$ occur in allergic people, $10 \%$ are associated with chronic conditions and $10 \%$ is due to immunodeficiency. This high rate of infections in children without comorbidities results from an immature immune system, associated with risk factors, such as increased exposure to various infectious agents during the early years of life..$^{15}$ Thus, before raising the hypothesis of a PID, it is important to recognize the immaturity of the immune system to identify the risk factors that predispose RRI in healthy children (attendance to daycare centers, older siblings, exposure to cigarette smoke, air pollution, house with many people, low socioeconomic level), ${ }^{24}$ in addition to discarding underlying conditions that justify recurrent infections (Table 1$)^{1}$ and correctly diagnose pathologies whose symptoms may be confused with RRI such as rhinitis, asthma and gastroesophageal reflux disease. ${ }^{15}$

For a well-founded suspicion of a PID it is also necessary to recognize that infections in healthy children do not present many clinical repercussions and usually do not have prolonged or complicated course. In addition, the child feel well among the infectious episodes, presenting normal growth and development. ${ }^{12}$ In children with PIDs, the recurrent infections are caused by low virulence pathogens or by the same group of specific pathogens. Although the infectious episodes may have little clinical expression, they often manifest severely and may be fatal. In general, they present with prolonged evolution associated with delay in weight gain, inadequate response to commonly used antibiotic therapy and high risk of complications that require hospitalization. ${ }^{3}$

Table I Causes of recurrent infections in childhood, excluding PIDs

- High exposure to infectious agents: nurseries and schools; older siblings attending school

- Passive exposure to cigarette smoke

- Allergic diseases: asthma, rhinitis, atopic dermatitis

- Anatomical defects or presence of foreign body

- Gastroesophageal reflux disease

- Cystic fibrosis

- Secondary immunodeficiencies: malnutrition, AIDS, use of immunosuppressants, protein-losing enteropathy, intestinal lymphangiectasia, nephrotic syndrome, sickle cell anemia, asplenia, hypovitaminosis A, zinc deficiency, systemic lupus erythematosus and neoplasms

- Burns

- $\quad$ Exposed fractures

\section{Adapted from'}

The suspicion of a specific PID can be made with base in the clinical and microbiological characteristics of each major immunodeficiency group, such as: most commonly associated comorbidities, age of onset of infections, localization and pathogenic agents. ${ }^{15}$ The main characteristics of the main groups of PIDs are shown in Table 2. Children with cell-immunity deficiency are more susceptible to severe early-onset infections. Intracellular pathogens, such as typical and atypical mycobacteria, viruses, protozoa, fungi and salmonella are the most frequently involved. Additionally, a serious reaction to BCG vaccine is an important warning signal in neonates with $\mathrm{T}$ cell deficiency. ${ }^{7,12}$ The predominant antibody deficiencies occur about 5 to 12 months after the catabolism of the maternal antibodies, but they may also occur in late childhood or even in adulthood. ${ }^{1}$ Recurrent infections of the respiratory system caused by encapsulated and gastrointestinal extracellular bacteria, enteroviruses and Giardia lamblia are common in this type of PID. ${ }^{7,26}$

The phagocyte deficiencies manifest as recurrent abscesses and infections in the skin and in the respiratory, nervous and endothelial reticular systems. In these cases, the main microorganisms involved are: Staphylococcus, Gram-negative bacteria (Serratia, E. coli) and 
fungi (Candida, Aspergillus). The signs of early warning for this type of PID in newborns include delayed umbilical stump fall and impaired healing. ${ }^{15,21}$ Deficiencies in the terminal components of the complement system usually occur with serious infections that are associated with arthritis, meningitis and septicemia. Deficiency of central components of the complement(C3) predispose infections caused by pyogenic pathogens and deficiencies of the initial components are associated with autoimmune diseases. ${ }^{3}$

Table 2 Clinical and microbiological profile of the PIDs

\begin{tabular}{|c|c|c|c|c|}
\hline Feature & Cellular Deficiencies & Humoral Deficiencies & Phagocyte Deficiencies & $\begin{array}{l}\text { Complement } \\
\text { Deficiencies }\end{array}$ \\
\hline Onset age & Early (2-6 months of life) & $\begin{array}{l}\text { Early (5 to } 12 \text { months } \\
\text { or late childhood) older } \\
\text { children and adults }\end{array}$ & Early & Any age \\
\hline $\begin{array}{l}\text { Common } \\
\text { Pathogens }\end{array}$ & $\begin{array}{l}\text { Mycobacteria, } \\
\text { Pseudomonas, CMV, } \\
\text { EBV,vírus varicela zoster, } \\
\text { enterovírus, Candida, } P \text {. } \\
\text { carinii }\end{array}$ & $\begin{array}{l}\text { S. pneumoniae, Hib, S. } \\
\text { aureus, Campylobacter, } \\
\text { enterovírus, Giardia, } \\
\text { Criptosporidium }\end{array}$ & $\begin{array}{l}\text { S. aureus, Pseudomonas, } \\
\text { Serratia, Klebsiella, Candida, } \\
\text { Nocardia, Aspergillus }\end{array}$ & N.meningitidis, E.coli \\
\hline $\begin{array}{l}\text { Pathologic } \\
\text { features }\end{array}$ & $\begin{array}{l}\text { Inadequate growth, } \\
\text { diarrhea, persistent } \\
\text { candidiasis }\end{array}$ & $\begin{array}{l}\text { Sinopulmonary infections, } \\
\text { gastrointestinal } \\
\text { symptoms, arthritis, } \\
\text { meningoencephalitis }\end{array}$ & $\begin{array}{l}\text { Cellulitis, abscesses, } \\
\text { periodontitis, adenitis, } \\
\text { osteomyelitis }\end{array}$ & $\begin{array}{l}\text { Meningitis,arthritis, } \\
\text { septicemia, } \\
\text { sinopulmonary } \\
\text { infections }\end{array}$ \\
\hline $\begin{array}{l}\text { Special } \\
\text { features }\end{array}$ & $\begin{array}{l}\text { BCGitis, tetany, } \\
\text { hypocalcemia, graft versus } \\
\text { host disease }\end{array}$ & $\begin{array}{l}\text { Autoimmunity, lymphomas, } \\
\text { thymoma, paralysis by oral } \\
\text { polio vaccine }\end{array}$ & $\begin{array}{l}\text { Delay in umbilical stump fall, } \\
\text { impaired healing }\end{array}$ & $\begin{array}{l}\text { Vasculitis, systemic } \\
\text { lupus erythematosus, } \\
\text { dermatomyositis, } \\
\text { glomerulonephritis, } \\
\text { angioedema }\end{array}$ \\
\hline
\end{tabular}

Hib, type b Haemophilus influenzae; CMV, citomegalovirus; EBV, Epstein-Barr virus Adapted from ${ }^{28}$

Although recurrent infections are the most common manifestations of PIDs, other conditions may be associated with the disease and precede the onset of infections. The major non-infectious manifestations are ${ }^{7,15,26}$

a) Allergic: severe asthma, chronic urticaria, atopic eczema;

b) Gastrointestinal: inflammatory bowel disease, autoimmune enteropathy, chronic non-infectious diarrhea, celiac disease;

c) Hematologic: hemorrhages (plaquetopenia with chips), autoimmune cytopenias (thrombocytopenia, anemia, neutropenia);

d) Rheumatologic: immunocomplex mediated autoimmune diseases;

e) Endocrinopathies: type I diabetes mellitus, thyroid disease, hypoparathyroidism;

f) Neoplastic (lymphohematopoietic system);

g) Non-allergic angioedema (without urticaria).

The clinical history of the patient is essential for suspicion of a PID and should be detailed, containing information related to infectious episodes such as age of onset, frequency, duration, severity, predominant site, probable etiology, response to treatment, complications and associated comorbidities. ${ }^{6,20}$

The family history is extremely important for suspected PID, including the occurrence of death caused by severe infection, cases of recurrent infections, auto-immunities, neoplasms or serious reactions to vaccines in siblings or other children of the family. In addition, the presence of consanguinity between parents and spontaneous abortion with no known cause in maternal history should be investigated. However, a negative family history cannot exclude a possibility of PID, because a new mutation may be involved in the origin of the disease..$^{20,27,28}$

The physical examination should be detailed, careful and complete and the following aspects deserve special attention:

a) Weight-height development-Weight and height should always be evaluated, as recurrent or chronic infections that occur in PIDs can affect the growth of the children. In this case, removing secondary munodeficiency due to malnutrition, becomes relevant ${ }^{10}$

b) Lymphoid tissues/organs-palpation of the lymph nodes is essential in the examination, since diseases such as complete DiGeorge syndrome, X-linked maglobulinemia and severe combined unodeficiencies can occur with absence of palpable lymph nodes in addition to palatine tonsils and hypo-developed or absent adenoids. However, unodeficiencies that present with erinflammatory disease such as chronic granulomatous disease, AIDS, variable common munodeficiency present with increased lymphoid tissue such as adenomegaly and osplenomegaly ${ }^{10}$

c) Skin changes-specific skin lesions are commonly associated with certain diseases, such as petechiae and eczemas in WiskottAldrich syndrome; dermatitis and generalized rash in severe combined unodeficiency; chronic pruritic eczema in hyperIgE syndrome; oral ulcers and gingiastomatitis in quantitative or qualitative deficiencies of phagocytes; telangiectasias in the ataxia-telangiectasia syndrome and partial oculocutaneous albinism in Chédiak-Higashi syndrome. ${ }^{3}$

d) Syndromic stigmas-many genetic syndromes are associated with immune defects and the identification of abnormal phenotypic features may aid in suspected PID. For example, facial dysmorphism with low ear implantation, hypertelorism, micrognathia, bifid uvula, antimongoloid otic fold and congenital heart disease are common in the DiGeorge syndrome. Patients 
with Down syndrome, Bloom's syndrome and Turner syndrome may also present nodeficiencies. ${ }^{3}$

Because of the many features that can be used as warning signs, the Jeffrey Modell Foundation and American Red Cross published a report in 1999 with the Ten Signs of Alert for Primary munodeficiency, to assist the clinical reasoning about the patients that need undergo laboratory investigation. These signs were adapted to the Brazilian patients by the Brazilian munodeficiency Group (BRAGID), ${ }^{9}$ as demonstrated in Table 3. Some types of PID may evolve mildly, with the onset of symptoms manifesting only in adulthood, especially in cases of common variable munodeficiency, in which most clinical manifestations occur at the 2 nd and 3rd decade of life. ${ }^{30}$ The warning signs for PID in the adult adapted to the Brazilian patients by BRAGID are shown in Table 4 . The Laboratory investigation becomes mandatory if the presence of one or more of the Ten Warning Signs is observed. ${ }^{9}$

Table 3 Warning signs for PID in the childhood

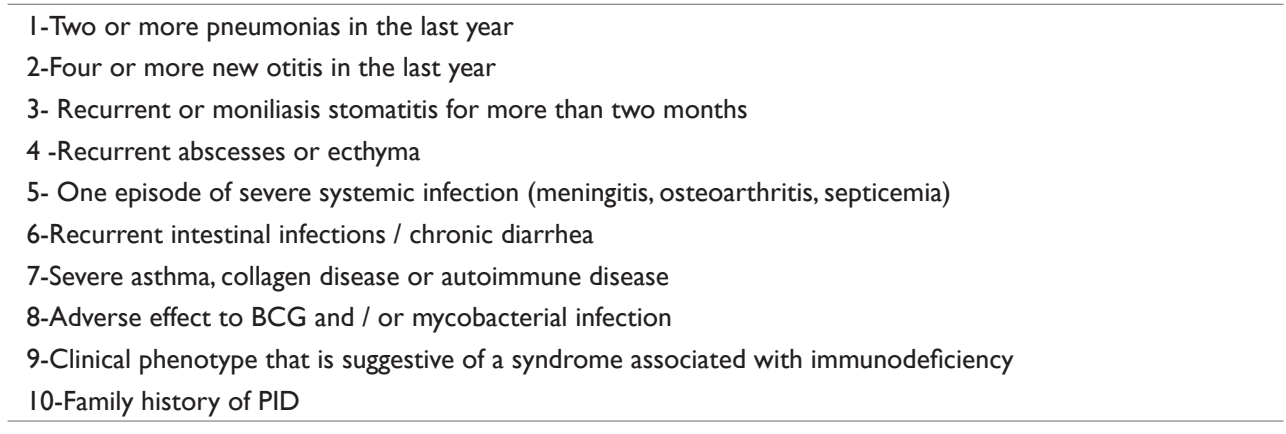

Adapted from ${ }^{29}$

Table 4 Warning signs for adult PID
I. Two or more new ear infections in I year
2. Two or more new sinusitis in I year in the absence of allergy
3. One pneumonia per year for more than I year
4. Chronic diarrhea with weight loss
5. Recurrent viral infections (colds, herpes, warts, condyloma)
6. Repeated use of intravenous antibiotics to treat infection
7.Deep recurrent abscesses in the skin or internal organs
8. Persistent moniliasis or fungal infection on the skin or anywhere
9. Mycobacterium tuberculosis or atypical infection
10. Family history of immunodeficiency

Adapted from ${ }^{29}$

\section{Initial investigation and how to lead}

The initial investigation with laboratory tests should be performed according to the suspected diagnosis and based on the clinical history and physical examination of the patient. In addition, the identification of the pathogen that is most involved in recurrent infections may be useful in the investigation of a particular type of PID. ${ }^{7,10,15}$ The screening should initially include a minimum number of tests the following desirable characteristics: high sensitivity, high availability, easy execution and low cost. ${ }^{31}$ Regardless of the type of PID suspected, all examinations that are shown in Table 5 should be initially requested. ${ }^{7}$

Table 5 Initial examinations of a suspected PID

- Complete blood count

- Immunoglobulin serum levels: $\lg G, \lg A$ and $\lg M$

- $\quad$ Delayed Hypersensitivity Skin Test (PPD)

Adapted from ${ }^{7}$
A complete blood count with differential leukocyte counts is important for all patients with suspected PID, because it provides important information, such as cytopenias or increase in one of the series. $^{7,31,32}$ By the other hand, a serum immunoglobulin dosage provides important information on suspected humoral deficiency. For evaluation of cellular immunity, skin hypersensitivity tests are very useful. ${ }^{7,3,33,34}$ In addition to the initial tests that are requested independent of the affected component, more specific and targeted tests should also be requested to confirm the suspected PID type. ${ }^{7,34,35}$ In the case of suspected humoral deficiency, in addition to the analysis of serum immunoglobulins, an evaluation of IgG subclasses, functional evaluation of immunoglobulins, antibody titration to polysaccharide antigens, and evaluation of B lymphocytes can be performed. Finally, flow cytometry, complement analysis, and neutrophil function testing are also important (Table 6). ${ }^{7,22,32,36}$

According to the levels of immunoglobulins, the following hypotheses can be raised: a) normal $\operatorname{IgG}$ and $\operatorname{IgM}$ and decreased $\operatorname{IgA}=\operatorname{IgA}$ deficiency; b) decreased $\operatorname{IgG}$ and $\operatorname{IgA}$ and increased $\operatorname{IgM}=$ Hyper-IgM syndrome; c) normal $\operatorname{IgG}$ and $\operatorname{IgA}$ and decreased $\operatorname{IgM}=\operatorname{IgM}$ deficiency; d) decreased $\operatorname{IgG}, \operatorname{IgM}$ and $\operatorname{IgA}=$ hypogammaglobulinemia. In cases of hypogammaglobulinemia, a B cell analysis is indicated. ${ }^{7,24,37}$ 
The evaluation of $\operatorname{IgM}$ funcionality can be performed by investigating the antibodies with antigen-specific response to the $\mathrm{ABO}$ blood group. Infants with age $>6$ months produce these antibodies. On the other hand, the functional evaluation of the $\mathrm{IgG}$ class can be inferred through the search for antibodies with specificity for vaccine antigens, such as tetanus, polio, measles and rubella. If the aforementioned exams present normal results and the patient continues with a clinical suggestion of humoral immunodeficiency, the next step is to evaluate the specific response against polysaccharide antigens. ${ }^{7}$ In this case, for a correct evaluation, it is necessary to dose the level of immunoglobulins before the pneumococcal vaccination and about 4-8 weeks later. A comparison of the pre and post immunization immunoglobulins against each serotype should be performed to evaluate a suitable response to this bacterium (antibody levels $>1.3$ $\mathrm{mcg} / \mathrm{ml}$ or 4 fold higher than the post-pre-immunization value). ${ }^{7,35}$ Antibodies of the IgG1 and IgG3 subclasses reflect the thymusdependent response. In other words, this represents the ability to react against protein antigens. The IgG4 subclass, however, reflects the independent thymus response, wgich is characterized by the reaction to polysaccharide antigens. ${ }^{34,38}$ As the test is more expensive and less informative than the determination of specific antibodies, this last test is more indicated. ${ }^{7}$

Table 6 Evaluation of humoral immunity

Initial Exams:
- Dosage of serum $\operatorname{lgG}, \lg A, \lg M$
- $\quad$ Dsage of Isohemagglutinins
- Dosage of vaccine antibodies (Rubella, Poliovirus, Measles)
Complementary Exams:
- $\quad$ Antibodies after vaccines with polysaccharide antigens (pneu-
- $\quad$ Igococci)
- $\quad$ Quantification of B cells (CD 19)

Adapted from ${ }^{7}$

In patients with hypogammaglobulinemia, an evaluation of $\mathrm{B}$ cells should be performed, as defects in the maturation of these cells resuls in significantly reduced immunoglobulins. In this case, flow cytometry is used for identification of B cells and their different stages of maturation can be assessed by using monoclonal antibodies binded to surface markers. ${ }^{11}$ In the case of suspected cellular immunodeficiency, the examinations shown in Table 7 should be requested. ${ }^{7}$ The hemogram can provide important information such as presence of lymphopenia, when the lymphocyte counts reach 1000 to 1500 cells $/ \mathrm{mm}^{3}$ in infants. Chest radiography is useful in the evaluation of the thymic image, since it may be absent in diseases such as severe combined immunodeficiency. ${ }^{33,34}$ The late hypersensitivity cutaneous reaction (DTH) consists of an effective and simple method for evaluation of the cellular immunity. However, its limitation lies in the fact that prior sensitization with the tested antigens is required. Therefore, common antigens are used in these tests, including: PPD, candidin, varidases and tetanus. The response is considered positive when an erythematous reaction with formation of a nodule that progressively increases until reaching its maximum $24-48 \mathrm{~h}$ after inoculation is formed. ${ }^{7,33}$

Table 7 Evaluation of cellular immunity

\section{Initial Exams:}

- Hemogram: morphology and number of lymphocytes

- Chest radiography: evaluation of the thymic image

- Delayed hypersensitivity skin tests: PPD, Candidin, SK-SD, Tetanus

\section{Complementary Exams :}

- Quantification of T lymphocytes: CD3, CD4 and CD8

- Lymphoproliferative response and phytohemagglutinin (PHA)

\section{Adapted from ${ }^{7,34}$}

The identification and quantification of $\mathrm{T}$ cells in the peripheral blood can be performed by flow cytometry by using monoclonal antibodies against cell surface markers. The best marker for total $\mathrm{T}$ cell identification is the CD3 molecule, because it is present in all subpopulations of mature $\mathrm{T}$ lymphocytes. The characterization of $\mathrm{CD} 3+\mathrm{T}$ cells can be performed by identifying CD4+(helper cells) and CD8+(cytotoxic cells). NK cells can be identified through the CD16 and CD56 markers. ${ }^{11}$ The best way to qualitatively evaluate the T lymphocytes is by using in vitro proliferative response to mitogens as phytohemagglutinins, which specifically activate all T cells. A normal lymphoproliferative response reflects the integrity of the fundamental stages of the cellular response. In the case of a deficiency in the lymphoproliferative response, additional tests should be requested to identify which point is responsible for this unsatisfactory response. ${ }^{7}$ The phagocyte deficiencies are demonstrated by a defect in neutrophil recruitment, bactericidal activity or at any stage of phagocytosis. In this context, neutrophil defects can be quantitative or qualitative and the functional evaluation is only carried out in laboratories of high specialty. The initial examinations requested are given in Table $8 .^{7}$ A blood count quantitatively evaluates neutrophils and values below 1500 granulocytes $/ \mathrm{mm}^{3}$ determine neutropenia, the age and racial characteristics of the patient should be always considered.?

Table 8 Evaluation of phagocytes

$$
\begin{aligned}
& \text { Initial Exams: } \\
& \begin{array}{l}
\text { - Hemogram: number and morphology of neu- } \\
\text { trophils and monocytes }
\end{array} \\
& \text { - N.B.T.T test }
\end{aligned}
$$

\section{Adapted from ${ }^{7}$}

A qualitative analysis can be performed using the nitroblue tetrazolium (NBT) test, which is widely used in screenings for the Chronic Granulomatous Disease. This test consists in incubating the cells with NBT, which has a yellowish color and becomes dark blue when reduced by products derived from " burst", indicating positivity in the test as phagocytes present microbicidal activity. ${ }^{10,34}$ Flow cytometry is used to evaluate the presence of adhesion molecules on the surface of leukocytes. Thus, a reduction in the CD18/CD11 expression reflects a leukocyte adhesion deficiency (LAD). The myeloperoxidase deficiency can be evaluated through the use of a peroxidase staining in the peripheral blood. ${ }^{7}$ The CH50 test is the most widely used to evaluate overall lithic activity, indicating the efficiency of the classical complement pathway (Table 9). When a reduction in the level of $\mathrm{CH} 50$ is observed, individual dosages of the proteins is 
indicated to identify which protein is deficient. ${ }^{15,31}$

Table 9 Evaluation of the complement

\section{Initial Exams:}

Total Hemolytic Complement (CH50)

\section{Adapted from ${ }^{7}$}

In Brazil, for all patients with recurrent infections, it is extremely important to request serology for HIV, considering the high prevalence of AIDS in this country. ${ }^{15}$ Any change in the initial screening tests or in the tests with normal results of patients with a high degree of clinical suspicion, excluded other causes of recurrent infections, the patient should be referred immediately to reference centers for diagnosis and treatment of PIDs for an advanced immunological investigation, which is required before initiating a specific early treatment. ${ }^{10}$

\section{Treatment}

The therapeutic measures for patients with PIDs requires a multidisciplinary approach, being classified into general or specific. ${ }^{15}$ The general therapeutic measures consist in educate the patient and its family on conducts such as avoiding aglomerations and maintain strict personal and environmental hygiene, in addition to give information regarding the pathology, the vaccination with inactive agents, the aggressive antibiotic therapy according to the previously isolated pathogen, the treatment of comorbidities and complications. The specific therapeutic measures differ according to the type of PID and comprise the following procedures. ${ }^{3,33}$

a) Immunoglobulin replacement therapy: preparations containing neutralizing antibodies against a wide variety of microorganisms, reflecting the immunological memory of the donors. The administration may be intravenously or subcutaneously. Patients with humoral immunodeficiency benefit from this type of therapy. ${ }^{39}$

b) Bone marrow or stem cell transplantation: it is the main treatment for severe combined immunodeficiencies and cellular immunodeficiencies. It may also be useful in other PIDs such as phagocyte defects, Chediak-Higashi syndrome and WiskottAldrich syndrome. ${ }^{40}$

c) Imunomodulators: they act in the immunological system conferring greater organic response. Cytokines such as IFN- $\gamma$ and granulocyte colony-stimulating factor are crucial for some types of PID such as chronic granulomatous disease and congenital neutropenias, respectively. ${ }^{33}$

d) Enzyme replacement therapy: it benefits patients with adenosine deaminase deficiency (ADA), a type of severe combined immunodeficiency. ${ }^{33}$

e) Gene therapy: replacement of the defective gene with a normal copy of the mutated gene through retroviral vectors thus correcting the disease phenotype. It represents the most promising therapy for some serious PIDs. ${ }^{41}$

\section{Conclusions}

Children exhibits physiological immaturity of immunity, which reaches full development only in the adolescence. Therefore, significant episodes of recurrent infections can occur in the healthy child. Primary immunodeficiencies result from genetic defects in one or more components of the immune system, leading to recurrent infections as major manifestations. The onset of symptoms may occur in childhood or adulthood. Thus, these diseases are not restricted to the pediatric environment. Because of the different causes of recurrent infections in the childhood, it is necessary to define which aspect of the immune system is worthy of investigation.

The Ten Warning Signs for adult and child were created to aid in the medical reasoning about the need for laboratory investigation in certain patients. However, this instrument should be critically applied, considering aspects such as severity of the infections and exclusion of underlying pathologies that may favor recurrence infections. The clinical history of the patient should be always considered. An anamnesis to collect data such as clinical history including the characteristics of infections, comorbidities and family history, associated to a thorough physical examination that involves assessment of weight and height development, lymphoid tissues, skin changes and syndromic stigmas, are essential for a well-founded suspicion of PID, favoring the initial laboratory investigation necessary for the diagnosis.

The initial laboratory investigation should be performed using simple and low-cost examinations directed to the type of PID that is suspected. Complete blood counts, determination of immunoglobulin levels and delayed hypersensitivity skin tests provide valuable information for the disposal of several primary immunodeficiencies. These tests are offered by most health services, and thus, the main difficulty for starting an investigation is not related to the lack of technologies, but to the lack of a consistent suspicion by some professionals in the primary care. Specific treatments differ according to the type of PID and currently comprise immunoglobulin replacement therapy, bone marrow or stem cell transplantation, use of immunomodulators, enzyme replacement therapy and gene therapy.

\section{Acknowledgments}

None.

\section{Conflicts of interest}

The author declares there are no conflicts of interest.

\section{References}

1. Vilela MM. Child immune system development: allergy and immunology in childhood and adolescence 2 edn. Sao Paulo: Atheneu. 2009.

2. Goenka A, Kollmann TR. Development of immunity in early life. $J$ Infect. 2015;71(Supply 1):112-120.

3. Morimoto Y, Routes JM. Immunodeficiency overview. Primary Care: clinics in office practice. 2008;35(1):159-173.

4. Errante PR, Perazzio SF, Frazão JB, et al. Primary immunodeficiency association with systemic lupus erythematosus: review of literature and lessons learned by the Rheumatology Division of a tertiary university hospital at São Paulo, Brazil. Revista Brasileira de Reumatologia. 2016;58-68.

5. Modell V, Knaus M, Modell F, et al. Global overview of primary immunodeficiencies: a report from Jeffrey Modell Centers worldwide focused on diagnosis, treatment, and discovery. Immunol Res. 2014;60(1):132-144. 
6. Roxo Júnior P, Ferreira RA. Clinical and Regulatory Protocol for Children with Recurrent Infections. Clinical and Regulatory Protocols: health network access. Rio de Janeiro: Elsevier. 2012.

7. Carvalho B, Nudelman V, Sampaio MM. Immune System Laboratory Assessment. Jornal de Pediatria. 2010;3-11.

8. Naik S, Nicholas SK, Martinez CA, et al. Adoptive immunotherapy for primary immunodeficiency disorders with virus-specific T lymphocytes. J Allergy Clin Immunol. 2016;137(5):1498-1505.

9. Carvalho BT, Roxo Júnior P, Tavares FS. How to approach the child with recurrent respiratory infection. Pediatric Society. 2008;24:343.

10. Ferreira JF. Primary immunodeficiencies in childhood - When should pediatricians suspect and how should they conduct themselves? Revista de Saúde da Criança e do Adolescente. 2011;3(1):58-62.

11. Abbas AK, Lichtman AH, Pillai S. Cellular and molecular immunology. 8 edn. 2015.

12. Roxo Júnior P, Carvalho BT, Tavares FS. Recurrent infections: what is important to pediatricians. Revista Paulista de Pediatria. 2009;27(4):430-435.

13. Latiff Ah, Kerr Ma. The clinical significance of immunoglobulin A deficiency. Ann Clin Biochem. 2007;44(Pt 2):131-139.

14. Clarke SC. Control of pneumococcal disease in the United Kingdomthe start of a new era. J Med Microbiol. 2006;55(8):975-980.

15. Roxo Júnior Pr. Primary immunodeficiency diseases: relevant aspects for pulmonologists. Jornal Brasileiro de Pneumologia. 2009;35(10):10081017.

16. Notarangelo LD. International Union of Immunological Societies Expert Committee on Primary Immuno deficiencies. Journal of Allergy and Clinical Immunology. 2010;125(3):771-773.

17. Shearer WT, Fischer A. The last 80 years in primary immunodeficiency: how far have we come, how far need we go? J Allergy Clin Immunol. 2006;117(4):748-752.

18. Aghamohammadi A, Mohammadinejad $\mathrm{P}, \mathrm{Abolhassani} \mathrm{H}$, et al. Primary Immunodeficiency Disorders in Iran: Update and New Insights from the Third Report of the National Registry. J Clin Immunol. 2014;34(4):478490.

19. Batalha SE. Primary Immunodeficiencies - Pathophysiology Review, Classification, Approach. Revista Saúde Infantil. 2011;33(3):97-102.

20. Ochs HD, Hagin D. Primary immunodeficiency disorders: general classification, new molecular insights, and practical approach to diagnosis and treatment. Ann Allergy Asthma Immunol. 2014;112(6):489-495.

21. Bousfiha A, Jeddane L, Picard C, et al. The 2017 IUIS Phenotypic Classification for Primary Immunodeficiencies. J Clin Immunol. 2018;38(1):129-143.

22. Brodszki N, Jönsson G, Skattum L, et al. Primary immunodeficiency in infection-prone children in southern Sweden: occurrence, clinical characteristics and immunological findings. BMC Immunol. 2014;15(31):1-9.
23. De Martino M, Ballotti S. The child with recurrent respiratory infections: normal or not? Pediatr Allergy Immunol. 2007;18(Suppl 18):13-18.

24. Roxo Júnior P. When to think about primary immunodeficiency. 2018.

25. Conley ME. Primary B cell immunodeficiencies: comparisons and contrasts. Аnпu Rev Immunol. 2009;27:199-227.

26. Chinen JE. Long-term follow-up of patients with primary immunodeficiencies. Journal of Allergy and Clinical Immunology. 2007;120(4):795-797.

27. Al Herz W, Aldhekri H, Barbouche MR, et al. Consanguinity and Primary mmunodeficiencies. Hum Hered. 2014;77(1-4):138-143.

28. Roxo Junior P, Silva J, Andrea M, et al. A family history of serious complications due to BCG vaccination is a tool for the early diagnosis of severe primary immunodeficiency. Ital J Pediatr. 2013;39:54

29. Brazilian Group For Immunodeficiency.

30. Bruno Rampelotto Botton, Eloísa Unfer Schmitt, Gustavo Trindade Michel, et al. Late diagnosis of variable common immunodeficiency. Revista da AMRIGS. 2010;54(4):461-465.

31. Vavoltarelli J, Donadi E. Clinical immunology in medical practice. 2008.

32. Roxo Júnior P, Ferriani VP, Grumach AS. Primary immunodeficiencies. Clinical immunology in medical practice. 2009.

33. Vasconcelos DM, Nudelman V. Predominantly cellular immunodeficiencies. Allergy and immunodeficiencies in pediatricpractical approach. Ribeirao Preto: Tecmedd. 2016.

34. Pires EM, Troster EJ, Brandão AC, et al. Care Guidelines Primary Immunodeficiencies: When and How to Investigate. 2012.

35. Costa Carvalho BT, Grumach AS, Franco JL, et al. Attending to Warning Signs of Primary Immunodeficiency Diseases Across the Range of Clinical Practice. J Clin Immunol. 2014;34(1):10-22.

36. Moens LN, Falk Sörqvist E, Asplund AC, et al. Diagnostics of Primary Immunodeficiency Diseases: A Sequencing Capture Approach. PLoS One. 2014;9(12):114901.

37. Chapel H. Classification of primary immunodeficiency diseases by the International Union of Immunological Societies (IUIS) Expert Committee on Primary Immunodeficiency 2011. Clin Exp Immunol. 2012;168(1):58-59.

38. Roxo Júnior P, Sorensen RU. Predominantly humoral immunodeficiencies. Allergy and immunodeficiencies in pediatrics practical approach. Ribeirao Preto: Tecmedd. 2006.

39. Nobre FA. Impact of intravenous human immunoglobulin treatment on the number of pneumonias in antibody-deficient patients. Revista Brasileira de Alergia e Imunopatologia. 2012;35:25-29.

40. Juliana Cantagalli Pfisterer, Sabrina Vargas Martini, Paolo Ruggero Errante. Severe combined immunodeficiency: a literature review. Brazilian Journal Allergy and Immunology. 2014;2(2):56-65.

41. Oliveira CS, Guella MM, Barbosa FK. Gene therapy in DMD. UNILUS Ensino e Pesquisa. 2015;12(28):159. 